$17^{\text {th }}$ International Congress of Metrology, 11007 (2015)

DOI: $10.1051 /$ metrology / 201511007

(C) Owned by the authors, published by EDP Sciences, 2015

\title{
Lighting: Panorama of the capacities and Impact of Metrology on the development and the improvement of LED technology
}

\author{
Jean-Rémy FILTZ ${ }^{1}$, Jimmy DUBARD ${ }^{1}$, Dominique RENOUX ${ }^{1}$, \\ Caroline TO VAN TRANG ${ }^{1}$, Olivier ENOUF ${ }^{1}$, Jean GAUDEMER ${ }^{1}$ \\ 1-Laboratoire national de métrologie et d'essais, 29, Avenue Roger Hennequin, 78190 Trappes, Paris Area, France
}

\begin{abstract}
Résumé. Dans le cadre du contexte des économies d'énergie, le LNE a complété sa plateforme de mesure de rayonnement optiques afin d'étudier, caractériser les "LED » (Light Emitting Diode) et la nouvelle génération de sources «SSL » (Solid-State Lighting). Ces développements ont été motivés par une croissance rapide des besoins pour évaluer différents paramètres de cette nouvelle génération de sources d'éclairage. En parallèle et afin de mieux appréhender la situation, le LNE a conduit une étude en France parmi les acteurs industriels de ce domaine. Cet article synthétise les développements au LNE et l'intérêt de la métrologie pour servir le développement de la technologie « LED ».
\end{abstract}

\section{Introduction}

Since the early 2000s, LNE has been completing its tools and skills and especially its optical radiation measurement platform in order to study, characterize LED and the new generation SSL sources.

These innovations are guided today by the implementation of European directives to facilitate energy savings and energy efficiency of buildings or any system.

The laboratory has therefore developed new measurement methods to evaluate different aspects such as the technical performance, reliability, safety limits or to contribute to the development of new standards.

The final objective is to promote and facilitate the adoption of new SSL technologies by any user.

Therefore, in the context of research and international cooperation programs with other metrology institutes or manufacturers, from Europe, Asia or America, this paper proposes to summarize the main actions carried out at LNE.

\section{Innovative Lighting}

The lighting market is facing a revolution of lighting source technologies. After the deployment of CFLs (Compact Fluorescent Lamps) and improved QTH (Quartz Tungsten Halogen) lamps, promising and outperforming solutions, in terms of integration, eco-design and/or efficiency, emerged from solid-state components: LED (Light Emitting Diode) and OLED (Organic Light Emitting Diode).

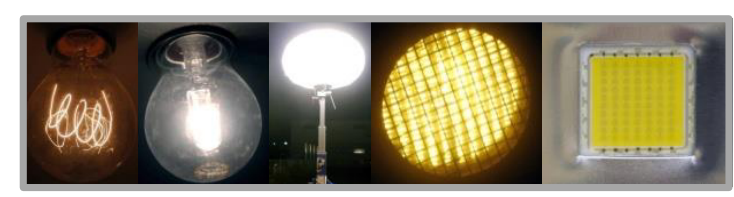

Figure 1 (from left to right): Technologies; Incandescent, Halogen, Halogen or

Hydrargyrum Medium-arc lodide, LED, Die

with phosphor. Source: Photos J.-R. Filtz collection

Competitive and innovative luminaires, based on high brightness LED, have now reached the domestic, architectural and public infrastructure markets. Continuous performance improvements are announced by the lighting industries.

The banishing policy of states for the low energy class of lamps raises interest in the 
energy saving and eco-friendly potential of SSL (Solid-State Lighting).

Therefore a new generation of reference standards for lighting source measurements have been developing and studying.

To contribute to these developments, LNE has been working on SSL innovations with several Manufacturers, Laboratories,... at the national and international levels with the objective to improve or set up metrics in that field, to transfer knowledge and to provide metrology services (assistance, measuring performances, safety assessment,...) for accelerating time to market of high-performance Lighting systems.

\section{Metrology and benchmarking}

Face to these societal and industrial stakes, in parallel to the scientific and technical developments performed at LNE and in order to better understand the market needs, LNE has been leading a first limited survey in France among the industrial players, a priori, interested by LED technologies [1].

The objective was to target the measurement needs and to adapt the research and practical measurement methods waited by industry and in order to allow improving the competitiveness among measurement laboratories.

\subsection{Targets and profiles}

About 70 customer targets have been identified and contacted for answering to a questionnaire (Figure 2).

The questionnaire was presented to a selected industrial panel taking into account the activity profile and of the society annual turnover (AT).

$$
\begin{array}{cr}
4 \%: & \text { AT }<100 k € \\
11 \%: & 100 \mathrm{k} €<\text { AT }<1 \mathrm{M} € \\
\text { 41\%: } & 1 \mathrm{M} €<\mathrm{AT}<10 \mathrm{M} € \\
33 \%: & 10 \mathrm{M} €<\mathrm{AT}<50 \mathrm{M} € \\
11 \%: & \mathrm{AT}>50 \mathrm{M} €
\end{array}
$$

Excepted the questioned population having rejected the questionnaire, this investigation mainly reveals at least 2 kind of industry families. First, those involved in the LED Supply chain, composed of Materials suppliers and Equipment suppliers (Manufacturers, Integrators) and secondly those who distribute the products for intermediate use or for end use. (Importers, Distributors...)
Therefore the integrators can be considered as equipment suppliers for direct end use (i.e.: luminaire) or for integration in a product (i.e.: headlights for automotive).

It can be considered that the distributors, retailers are included in the same chain with the importers.

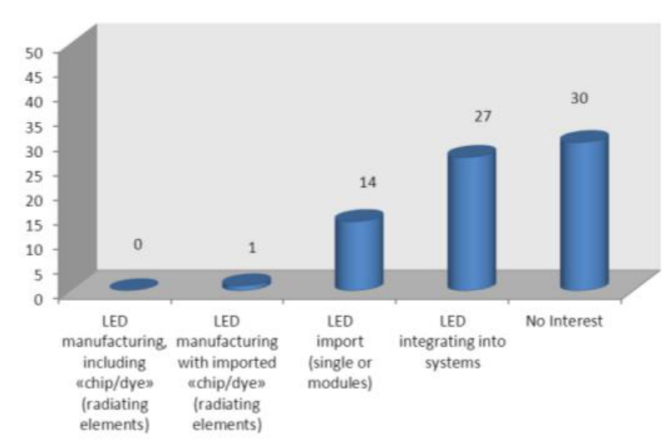

Figure 2: Targets - Profiles

\subsection{Field of application}

Defining the field of LED applications is quite complicated.

For instance, the LEDs can be used for indoor lighting of buildings or outdoor lighting of cities (street lighting) but also for any electronic application (Figure 3: as indicator for safety, road light signs, traffic lights or for defining an information status, displays...) or for transportation applications (headlights for automotive, lighthouses for the navy, beacons for airplanes and airports...).

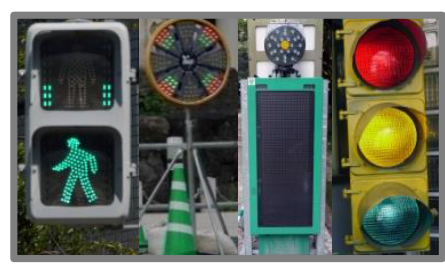

Figure 3: Road light signs Source: Photos J.-R. Filtz collection

According to the end use application, it is thus easy to understand that LED components or lighting systems can often be used for photonics or also electronics applications and, mainly suitable, motivated and guided by lighting innovations.

As described by the findings reported Figure 4, in the following chapters, we decided to focus our developments on lighting in general and in particular, safety or impact aspects. 


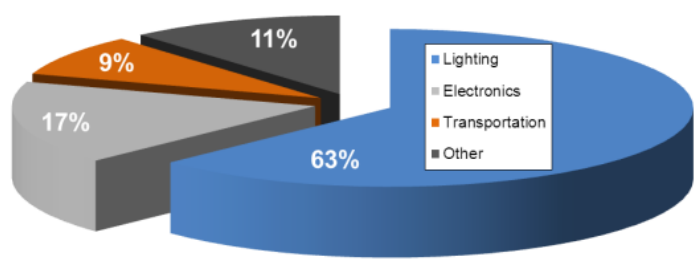

Figure 4: Field of application

\subsection{Measurement needs}

What are the Industry measurement needs?

The interests and priorities described by the targets depend on the final application.

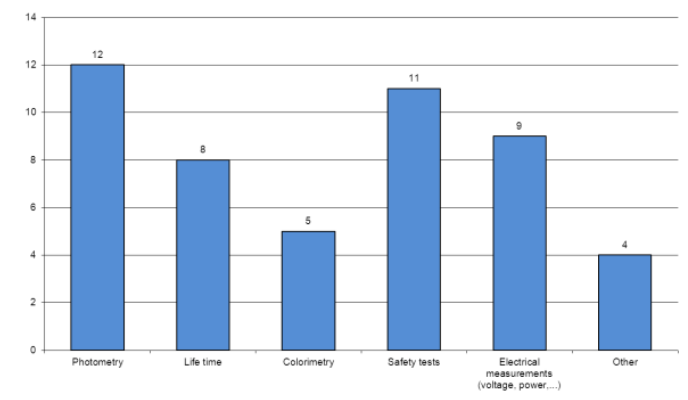

Figure 5: Measurement needs

However, from Figure 5 at least 5 families of needs can be identified;

1) Performances

a. Photometry and derived quantity measurements (luminous flux, Color temperature, CRI, energy efficacy).

b. Electrical measurements (output voltage, power...)

2) Reliability

a. Life time

b. Mechanical or thermal tests

3) Safety

a. Electromagnetism properties

b. Photo-biological risks

c. Impact of light on circadian rhythm

4) Sustainability
a. Environmental
i. Lifecycle management
ii. Recycling, Ecological footprint
b. Energy management
i. Smart lighting (buildings, cities...)

\author{
ii. Smart grids \\ iii. Lighting control \\ c. Communication
i. Li-Fi; visible light communication (VLC)

5) Sensory Perception: (Figure 6) Art galleries, Architecture, Shops... and Lighting
a. Enhancement of cultural heritage and its protection
b. Enhancement of the consumer products (textiles, objects...)
c. Appearance measurements

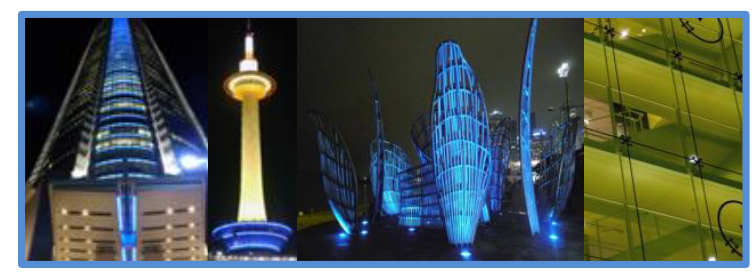

Figure 6: Lighting Enhancement

(i.e. Buildings, Monuments, Work of art, Shops...) Source: Photos J.-R. Filtz Collection

\subsection{Measuring the performances}

Depending on the measuring needs related to LED systems (tests, expertise, calibration, measurements, ...), it was identified that the measurements are performed or provided by at least 3 kinds of "service" societies; Internally or by outsourcing the service (Figure 7).

1) The Enterprise itself with support of their internal services.

2) The National Metrology Institutes or recognized measurement Laboratories.

3) Other societies.

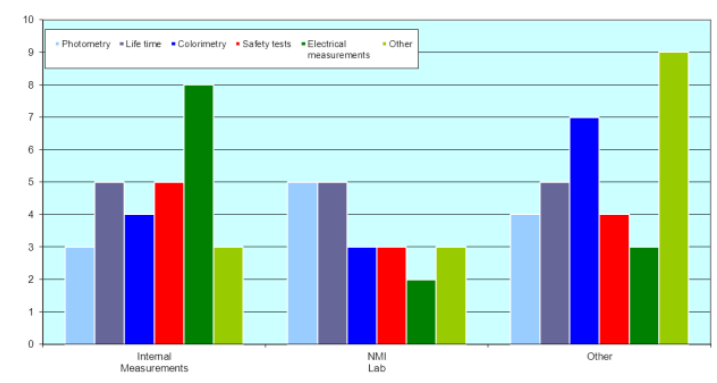

Figure 7: Measuring the performances

\subsection{Metrology impact - Benefits for industry}

Operating profits achieved by the enterprises for developing any LED products or components with support of the different metrology services available concern mainly quality, innovation, traceability and cost savings (Figure 8). 
Quality and Traceability: better managing a technical process with for instance better measurement instrumentation traceability or a better knowledge of LED technical performances allows improving the quality of any final product.

Innovation: linked to the previous benefits, allows any industrial of seizing new opportunities towards new markets.

Other impacts: standardization, technical or scientific expertise or training consultancy and any specific developments... are other support and solution sources that metrology services can provide.

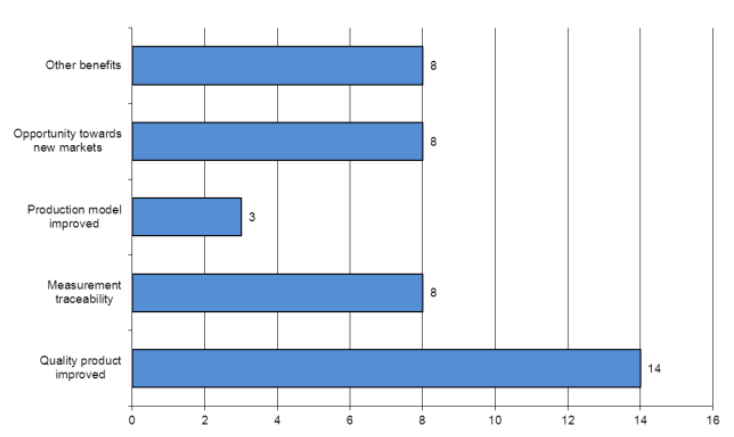

Figure 8: Impact - Metrology Benefits

\section{LED-based SLL and Metrology developments}

\subsection{Metrology for LED-based SSL}

Within different research projects performed at the National and the European level, The LNE has been developing new skills and facilities mainly set up in the lab called PISSARRO (Platform for Industry and Society providing Services, Assistance on products emitting optical radiations).

The research is continuously developed according to a Lighting roadmap summarized Figure 9.

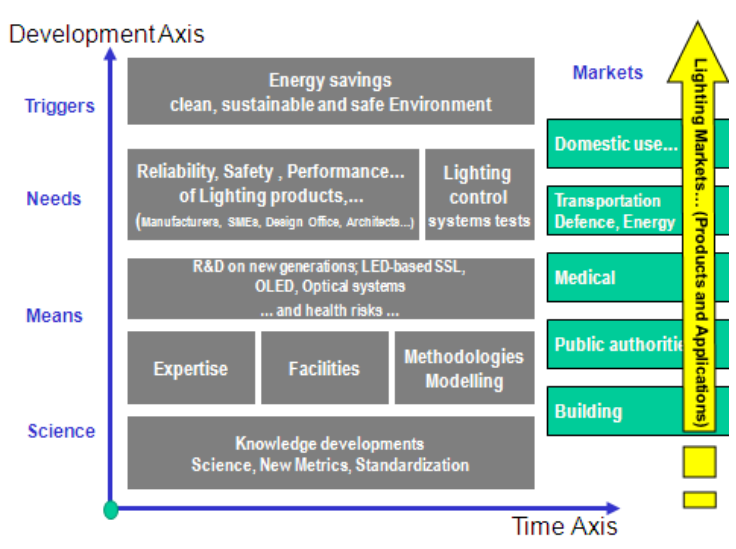

Figure 9: LNE Lighting Roadmap

As example, outputs from a European project allow in the following chapters to highlight the purpose [2].

\section{2 Life time characterization; example}

Within the framework of a Euramet/EMRP joint research project, ENG05, current facilities of the laboratory have been adapted and upgraded for performing aging tests.

Two experiments of accelerated aging during 6 months were performed in a climatic chamber at two different temperature levels $\left(45^{\circ} \mathrm{C}\right.$ and $\left.60^{\circ} \mathrm{C}\right)$.

Data processing has been compared to the natural aging performed by the National Metrology Institute of Finland.

The accelerated aging in a climatic chamber was observed for all tested lamps with speeds close or significantly different following the tested lamps but sufficiently uniform for retaining the proposed method as a useful tool for determining the life of LED-based SSL.

\subsection{Sensory perception}

\section{Subjective experiment:}

An experimental room was built. A lounge was furnished and decorated.

Twelve sets of sources can be installed on mobile trolleys above the ceiling of the room and light up the room through a translucent diffuser placed at the centre of the ceiling (Figure 10). 


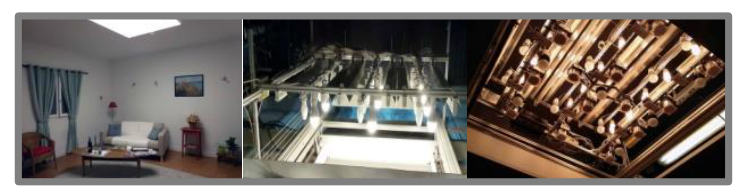

Figure 10: Sensory perception laboratory. (From left to right; Testing room, Top and

Bottom views of the versatile and mobile Lamp holder) Source: Source: Photos J.-R. Filtz Collection

43 observers participated in a subjective experience using 9 kind of lighting sources: incandescent, fluorescent, compact fluorescent and 6 types of LED technology lamps.

The evaluation criteria were focused on nine attributes: preference, quality of the colours identified as more vivid, colour fidelity, natural colours in general and on specific items (fruits, vegetables, plants, skin) and rendering of a colour chart.

A statistical analysis showed that the scientific experience was robust. The correlations of the subjective scores with predictions of the current metric and 13 new metric proposals were studied.

\section{Visual Comfort:}

Other experiments have been led at LNE. Practically a specific set of experiment rooms has been set up for studying the visual comfort [3]. Four subjective experiments were conducted with 50 participants: 17 lighting scenarios have been applied in a set made up of the living room, an office, a large room arranged in several compartments and a uniform background space with dazzling sources. The results are available at the Euramet website and reference [4].

\subsection{New Quality Metrix for LED-based SSL}

\section{Colour Rendering Index:}

A state of art was realized covering all the new colour rendering index proposals for replacing the current index.

Software was developed incorporating all the basic components of different metrics and allows the parametric analysis of the different colour rendering metrics. To estimate the impact of various metrics for the different lighting technologies, and the correlation between them, a set of 122 spectra sources was selected and classified by technology.
A general and comparative analysis was performed. Most metrics for the fluorescent sources studied present coherent results. (Pearson coefficient is about 0,90 ). However LEDs present lower correlation (Pearson coefficient is about 0,57 ). This shows that new metrics have to be constructed. This is the current R\&D work of the laboratory.

A recommendation for colour rendering metric was drafted and presented to the International Commission on Illumination (CIE)

\subsection{LED Metrology and Health risks}

Within the framework of a consortium, a state of art of photo-biological safety of the LEDs was achieved in parallel of some laboratory experiments led by LNE on the measurement methods. Main important results have been published by ANSES [5]

This study recommends developing adequate protective goggles especially adapted for workers exposed to LED sources.

UGR (Unified Glaring Rate) defined for classic lighting sources is not suitable for LEDs. Therefore, among the list of recommendation, it is suggested to develop R\&D for defining a relevant index enabling to estimate the "glaring" rate generated by a LED source. LNE develops its R\&D connected to this challenge.

Another investigation axis of the laboratory is linked to the standardization for LED [6]. The case of Blue Light Hazard has been studied by IEC TC 34 who published the IEC/TR 62778 "Application of IEC 62471 to light sources and luminaires for the assessment of blue light hazard.", (2012, revised 2014) [7]. This Technical report completes the standard IEC/EN 62471 for LED Lighting Products, especially for the assessment of the blue light hazard [8]. LNE has been investigating this topic related to the standard IEC 62471.

\section{Conclusions}

In 2015, LED technology continues to progress, offering always more performance and new applications. The lighting market is thereby widely changed: introduction of new regulations, more demanding in terms of performance (prohibition of halogen lamps in the near future), of new risks to consumer health (blue light), but above discovery new opportunities for the companies and the market players (innovative applications, research projects). 
This new period requires manufacturers, importers and distributors master the rules to ensure the conformity of their products, but also that they anticipate the normative changes, the regulatory and technological developments, and be prepared to new challenges of lighting [6].

Based on a significant experience in the area of photometry-radiometry, especially for the "mise en pratique" of the candela unit and also for the metrology of optical properties of materials for the realization of derived optical quantity scales, LNE has developed different unique facilities enabling the characterization of LEDs and LED integrated in systems.

To highlight this work, some technical developments and measurements performed at LNE have been presented as examples.

Furthermore this research programme aims finally to:

- propose traceable and accurate capabilities

- strengthen the technical protocols

- develop new metrics adapted to LED

- contribute to implement pre-normative studies (life time, rendering colouring index, visual comfort)

The LED manufacturers as well as for instance different industries such as Lighting, Electronics, and Automotive... can also take advantage of such metrology developments.

\section{Acknowledgements}

The LNE Marketing Department is greatly thanked for its support (§3). This part of the study was led within the framework of cooperation between France and Brazil (LNE/INMETRO).

The scientific and technical developments have been founding through the French and the European (EMRP/EMPIR) metrology research programmes $(\S 4)$.

\section{References}

[1] Metrology and LED Benchmarking, LNE Marketing Department, not published, 2014

[2] Metrology for Solid-State Lighting, Joint Research Project, ENG05, Final Report, Laboratoire commun de métrologie LNECNAM (LCM) - Photonics-Energy Division, D. Renoux, February 2014
[3] Prediction model for visual comfort of interior lighting J. Nonne, D. Renoux, L. Rossi, G. Rossi, to be published.

\section{[4] http://www.m4ssl.npl.co.uk/}

[5] Effets sanitaires des systèmes d'éclairage utilisant des diodes électroluminescentes (LED). Avis de l'Anses, Rapport d'expertise collective, Anses-Saisine $\mathrm{n}^{\circ}$ «2008-SA-0408», 2010

[6] Lighting: Regulations, R\&D and Innovation, Technical meeting, LNE, 2014

[7] Photobiological safety of lamps and lamp systems, CEI/IEC, International Standard 62471, CIE S 009:2002, First edition, 2006-07

[8] IEC TR 62778:2014; Application of IEC 62471 for the assessment of blue light hazard to light sources and luminaires, 2014 